\section{P6.23 USING MOBILE TECHNOLOGY TO INCREASE UPTAKE OF HIV AND STI PREVENTION TOOLS SUCH AS THE FC2 FEMALE CONDOM - A PUBLIC PRIVATE PARTNERSHIP FOR SECTOR LEARNING}

Tian Johnson. African Alliance for HIV Prevention, Johannesburg, South African Republic

\section{$10.1136 /$ sextrans-2017-053264.674}

Introduction Using mobile technology to increase access to and uptake of health information that translates into behaviour change is never easy. In partnership with The Female Health Company, The African Alliance for HIV Prevention developed and produced a 9 part web series designed to increase awareness and knowledge of as well as desire for the FC2 Female Condom - the only available tool for that a woman can initiate to protect herself from unplanned pregnancy, HIV and STI's - as part of Sexual and Reproductive Health and Rights Programming globally.

Methods Through the use of high profile and everyday people, from a range of backgrounds this series situates a life changing product in the social media and online space. A space where young people - especially in the global south are increasingly vulnerable to HIV and STI's. The series is unique in that, apart from providing the technical skills to the viewer to use, advocate for and programme the FC2 Female Condom, this series focuses on sexual pleasure as an entry point. The series, shot in the Masterclass style focuses on the speaker as they share poignant stories from the HIV and STI field as well as make the personal, programming, funding and political case for the FC2 Female Condom.

Results Shot in high definition and compact enough to fit on a flash drive this series has already had a profound effect on those who watch it and the first group of health care professionals will be trained using this series as a tool at the $8^{\text {th }}$ South African AIDS Conference. The results of an evaluation carried out the $8^{\mathrm{TH}}$ South African AIDS Conference will be released during the STI and HIV World Congress in Rio, 2017.

Conclusion In less then a decade, Sub Saharan Africa will have a higher penetration of mobile telephones then Northern America. This increase in access to technology and tools presents a unique opportunity for NGO's and the private sector to build awareness of and support access to essential HIV and STI prevention tools, such as the FC2 Female Condom.

\section{P6.24 THE FINANCIAL INCENTIVE TO MARKET SECONDARY PATENT OF RITONAVIR AND LOPINAVIR/RITONAVIR}

${ }^{1} \mathrm{~N}$ Vernaz, ${ }^{1} \mathrm{G}$ Cohen, ${ }^{1} \mathrm{C}$ Combescure, ${ }^{2} \mathrm{~B}$ Ledergerber, ${ }^{1} \mathrm{~A}$ Calmy. ${ }^{1}$ Geneva University Hospitals, Geneva, Switzerland; 'university of Zurich, Zurich, Switzerland

\subsection{6/sextrans-2017-053264.675}

Introduction The World Intellectual Property Organisation reported more than 9750 patents of ritonavir from the discovery in December 1993. This intellectual property right aimed to encourage innovation. However, heatstable formulations or combinations with other chemicals might be patented and marketed at higher price and also when the original patent is about to expire, a so called evergreening strategy. We aimed to determine the financial incentive of marketing heatstable formulation using the proprietary melt-extrusion (Meltrex) technology allowing in addition to reduce the pill count from 6 to 4 per day. The Meltrex technology was applied to ritonavir stand alone formulation in Oktober 2010 almost 4 years after the lopinavir/ritonavir (December 2006).

Methods Frequency of administration and dosage for all patients under ritonavir and lopinavir/ritonavir were collected from the Geneva Swiss HIV Cohort Study from January 2003 to June 2016. Extracosts were calculated for three different scenarios assuming the replacement with the corresponding Swiss market price de-escalation of (1) lamivudine (2) lamivudine/zidovudine and (3) efavirenz over time. Prices were adjusted by the inflation rate.

Results Over the study period the total cost was USD2,805,135 for the ritonavir and USD13,351,886 for the lopinavir/ritonavir. The increase in cost for the Meltrex technology per patient was $17 \%$ for ritonavir $4 \%$ for lopinavir/ ritonavir, leading to an extracost of USD166'358 and USD368'255 respectively.Theoretical savings if generic ritonavir would enter the market after original ritonavir patent termination would be USD994'080 for lamivudine price deescalation, USD750,917 for lamivudine/zidovudine and USD600,741 for efavirenz.

Conclusions The financial incentive encourage the pharmaceutical firm to be innovative leading to negotiate higher prices and at the same time to extent of the originator patent. The consequence is a financial impact for the society by preventing competition from generic equivalent and the delay in the accessibility of innovation for the patient.

\section{P6.25 CONVERGENCE CASE-MANAGEMENT FOR SYPHILIS CONTROL: A PILOT PROJECT IN CHINA}

Zhenzhou Luo. Shenzhen Nanshan Centre for Chronic Disease Control, Shenzhen - China Popular Republic

\subsection{6/sextrans-2017-053264.676}

Introduction The traditional syphilis control practice in China usually pays too much attention to treatment but neglects further management of syphilis cases, which could not effectively prevent spreading of the disease. In an attempt to address the problem, Nanshan district, Shenzhen, launched the Syphilis Convergence Case-management Project (SCCP) for the first time in China in April 2011. This pilot aimed to consolidate prevention, treatment and management. By far, the project has obtained some meaningfull outcomes and practical experience. Methods All the medical and public health faculties within the district are encouraged to refer syphilis seropositive cases to a centralised institution, which is responsible for providing standardised treatment, serologic follow-up (once every 3 months), partner tracing and health education, etc. We adopted some indices such as standardised treatment rate, follow-up rate and success rate of partner notification to evaluate the project.

Results By June 2016, the project has managed 1124 syphilis cases, among which 749 were newly treated cases. The standardised treatment rate for SCCP was $96.98 \%$. Compared to the historical level before (79.20\%). 3 months', 6 months', 1 year's and 2 years' follow-up rate were $76.33 \%, 62.40 \%$, $53.75 \%$ and $36.93 \%$, respectively, which were also significantly higher than those without convergence case-management $(P=0.01)$. Success rate of partner notification for managed patients were $83.92 \%$ (887). Among all the notified partners, $735(82.86 \%)$ received examination; 329 (44.76\%) 